Division of Pediatric Infectious Diseases, University of North Carolina School of Medicine, Chapel Hill, NC, USA

2 University of California Los Angeles, Mattel Children's Hospital, David Geffen School of Medicine, Los Angeles, CA, USA

Correspondence to: $Z$ Willis zwillis@med.unc.edu

Cite this as: BMJ 2022;376:n3093 http://dx.doi.org/10.1136/bmi.n3093 Published: 12 January 2022

\section{Covid-19 control measures and common paediatric infections}

\section{Hospital admissions fell substantially, probably reflecting a real decrease in non-covid infections Zachary Willis, ${ }^{1}$ Annabelle de St Maurice ${ }^{2}$}

Research, doi:10.1136/bmj-2021-067519

The covid-19 pandemic upended virtually all aspects of society, not least patterns of healthcare use. In a linked paper (doi:10.1136/bmj-2021-067519), Kadambari and colleagues report dramatic decreases in hospital admissions due to a range of 19 childhood infections in UK children in the 16 months after the start of the covid-19 pandemic. ${ }^{1}$ Almost all studied infections declined, including common respiratory viruses, vaccine preventable infections, and common bacterial infections. These findings support and expand data from the United States showing major decreases in childhood respiratory viruses. ${ }^{2}$

While some of the results might be expected, one surprising finding was the decrease in sporadic bacterial infections, osteomyelitis and septic arthritis, most commonly caused by Kingella kingae,

Staphylococcus aureus, and Streptococcus pyogenes. Although progression from pathogen acquisition to symptomatic infection in bacterial musculoskeletal infections is not well understood, conditions such as acute haematogenous osteomyelitis probably begin with colonisation of mucosal sites with the causative pathogen. ${ }^{3}$ Encounters with such pathogens were probably less frequent during the study period. Furthermore, co-occurringviral respiratory infections appear to increase the colonisation density of pneumococci and other pathogenic bacteria in the upper respiratory tract..$^{45}$ Therefore, it is conceivable that viral infections are a risk factor for invasive bacterial infections and a reduction in viral infections might help explain the decline in bacterial infections.

Another finding of interest was that although the absolute number of hospital admissions for pneumonia decreased by $60 \%$ during the pandemic, the proportion of patients admitted for pneumonia who died within 60 days increased from $1 \%$ to $2 \%$, with an adjusted odds ratio of 1.61 . While this finding could be secondary to disruptions in care due to a healthcare system under pressure, these data could also reflect changes in clinical practice; for example, children with less severe pneumonia being managed outside hospital. Reassuringly, no increases in mortality were observed for children admitted with any other infection type. Further research is needed to determine whether changes in delivery of care have affected clinical outcomes or healthcare costs.

Some limitations must be acknowledged when interpreting this study. Firstly, it is difficult to determine if some illnesses that might have ordinarily resulted in hospital admission were managed as outpatients. Secondly, Kadambari and colleagues' analyses relied on ICD-10 (international classification of diseases, 10th revision) codes of clinical diagnoses, but there is no reason to suspect that their findings can be attributed to changes in coding accuracy. Finally, it would be difficult to detect increased morbidity due to delayed care seeking for infections that usually require hospital admission but rarely result in death, such as septic arthritis.

If decreased care seeking were the primary driver of the reduction in infection related hospital admissions reported here, however, then we might expect a corresponding rise in infection related mortality, particularly with life threatening infections. In fact, other UK studies show an overall $10 \%$ decrease in child mortality and $51 \%$ decrease in infection related child mortality during the first year of the covid-19 pandemic. ${ }^{6}$

Kadambari and colleagues report that sepsis, a clinical syndrome more likely to develop with progression of an infection, also fell during the study period, suggesting that delayed presentation did not play an important part in their findings. Early in the covid-19 pandemic, healthcare avoidance and limitations on access probably led to a decrease in the diagnosis of certain infections, but convincing evidence now suggests that the apparent decreases shown here and elsewhere reflect true decreases in the incidence of infectious diseases.

These gains are likely to be temporary. Seasonally circulating viruses rely on growth in the size of the susceptible population caused by waning protective immunity in previously exposed people and the introduction of unexposed infants to that population. This might explain an unexpected outbreak of respiratory syncytial virus in the northern hemisphere during summer 2021, including in the UK, ${ }^{7}$ because children and infants had almost no exposure to respiratory syncytial virus due to lockdown measures in the preceding 15 months. As populations derive increasing protection from covid-19 through natural infections or vaccination, and measures such as lockdowns, mask mandates, and social distancing ease, there will probably be an increase in the incidence of primarily, but not exclusively, viral infections.

Economists often referred to a pent-up demand for goods and services as lockdown measures eased in Europe and North America during mid-2021. We might also see a similar catching up of common viral and bacterial infections, exacerbated by pandemic induced disruption of routine immunisation programmes, ${ }^{8}$ resulting in a continued and unpredictable strain on healthcare systems.

Kadambari and colleagues' study and others show that societies have greater control over the incidence of a wide range of infectious diseases than previously appreciated. Interventions that once seemed 
farfetched-universal mask wearing, protracted school and childcare closures, and travel restrictions-were implemented during the covid-19 pandemic. Unfortunately, some measures, including school closures, came with significant social and economic costs that are likely to increase health disparities. ${ }^{9}$

Understanding which mitigation strategies were most effective is key to reopening safely. For example, compared with other interventions, school closures probably had a minor role in controlling covid-19, ${ }^{10}$ while universal mask wearing appears to contribute substantially to reducing SARS-CoV-2 transmission within schools. ${ }^{11}$ As many mitigation measures are relaxed globally, controlled epidemiological studies to determine which interventions provide the greatest benefit for a wide range of infectious diseases should be a research priority.

Competing interests: We have read and understood the BMJ Group policy on declaration of interest and declare the following interests: ZW's institution has received grant funds from Merck and Co (Kenilworth, NJ) and Novavax (Gaithersburg, MD) to support work unrelated to this manuscript.

Provenance and peer review: Commissioned; not externally peer reviewed.

1 Kadambari S, Goldacre R, Morris E, etal. Indirect effects of the covid-19 pandemic on childhood infection in England: population based observational study. BMJ 2022;376:e067519.pmid: 34404718

2 Olsen SJ, Winn AK, Budd AP, etal. Changes in influenza and other respiratory virus activity during the COVID-19 pandemic-United States, 2020-2021. MMWR Morb Mortal Wkly Rep 2021;70:1013-9. doi: 10.15585/mmwr.mm7029a1. pmid: 34292924

3 Kiang KM, Ogunmodede F, Juni BA, etal. Outbreak of osteomyelitis/septic arthritis caused by Kingella kingae among child care center attendees. Pediatrics 2005;116:e206-13. doi: 10.1542/peds.2004-2051. pmid: 16024681

4 Howard LM, Zhu Y, Griffin MR, etal. Nasopharyngeal pneumococcal density during asymptomatic respiratory virus infection and risk for subsequent acute respiratory illness. Emerg Infect Dis 2019;25:2040-7. doi: 10.3201/eid2511.190157. pmid: 31625844

5 DeMuri GP, Gern JE, Eickhoff JC, Lynch SV, Wald ER. Dynamics of bacterial colonization with Streptococcus pneumoniae, Haemophilus influenzae, and Moraxella catarrhalis during symptomatic and asymptomatic viral upper respiratory tract infection. Clin Infect Dis 2018;66:1045-53. doi: 10.1093/cid/cix941. pmid: 29121208

6 Odd D, Stoianova S, Williams T, etal. Child mortality in England during the first year of the COVID-19 pandemic.Arc Dis Child 2021. doi: 10.1136/archdischild-2021-323370

7 Hussan F, Kotecha S, Edward MO. RSV bronchiolitis season 2021 has arrived, so be prepared! Arc Dis Child 2021;106:e51. doi: 10.1136/archdischild-2021-322835 pmid: 32845739

8 Dinleyici EC, Borrow R, Safadi MAP, van Damme P, Munoz FM. Vaccines and routine immunization strategies during the COVID-19 pandemic. Hum Vaccin Immunother 2021;17:400-7. doi: 10.1080/21645515.2020.1804776. pmid: 32845739

9 Hawrilenko M, Kroshus E, Tandon P, Christakis D. The association between school closures and child mental health during COVID-19. JAMA Netw Open 2021;4:e2124092. doi: 10.1001/jamanetworkopen.2021.24092. pmid: 34477850

10 Walsh S, Chowdhury A, Braithwaite V, etal. Do school closures and school reopenings affect community transmission of COVID-19? A systematic review of observational studies. BMJ Open 2021:11:e053371. doi: 10.1136/bmjopen-2021-053371. pmid: 34404718

11 Budzyn SE. Pediatric COVID-19 cases in counties with and without school mask requirements-United States, July 1-September 4, 2021. MMWRMorb Mortal Wkly Rep 2021;70. doi: $10.15585 / \mathrm{mmwr}$.mm7039e3 pmid: 34404718

This is an Open Access article distributed in accordance with the Creative Commons Attribution Non Commercial (CC BY-NC 4.0) license, which permits others to distribute, remix, adapt, build upon this work non-commercially, and license their derivative works on different terms, provided the original work is properly cited and the use is non-commercial. See: http://creativecommons.org/licenses/bync/4.0/. 